Maxwell, C. (2006) 'Context and 'contextualisation' in sex and relationships education', Health Education, 106(6): 437-449.

\title{
Context and 'contextualisation' in sex and relationships education
}

Claire Maxwell

Address for correspondence:

Thomas Coram Research Unit, Institute of Education, University of London, 27/28

Woburn Square, London WC1H 0AA, UK. Telephone 020-7612 6957 Email

c.maxwell@ioe.ac.uk

Claire Maxwell is a Research Officer in the Thomas Coram Research Unit at the Institute of Education, University of London 
Maxwell, C. (2006) 'Context and 'contextualisation' in sex and relationships education', Health Education, 106(6): 437-449.

\title{
Context and 'contextualisation' in sex and relationships education
}

\begin{abstract}
Purpose - This paper aims to contribute to growing efforts to 'contextualise' young people's experiences of sexual and intimate relationships in research and sex and relationships education (SRE). The study reported upon explored which factors young people identified as influencing their relationships - in the past, present and future.
\end{abstract}

Design/methodology/approach - An exploratory, qualitative investigation was conducted using focus groups and in-depth interviews to elicit young people's attitudes to, and experiences of, intimate relationships. A diverse group of young men and women $(\mathrm{N}=52)$ were purposively sampled from a range of agencies, including supported accommodation units, a young offenders' institution and two boarding schools.

Findings - Peer groups, a need for protection and companionship, and previous negative relationships variously influenced young people's experiences in early youth. Access to potential partners, other priorities, and the degree to which young people could offer a critical assessment of a relationship played a role in explaining current relationship attitudes and experiences. Future aspirations for sexual and intimate relationships were largely influenced by young people's broader plans for their education and transition into adulthood.

Practical implications - Age-appropriate and personally relevant forms of SRE need to be developed which focus on the various factors influencing relationships at different points in time for groups of young people.

Originality/value - Contextualising young people's sexual and intimate relationships in terms of the specific factors influencing attitudes, experiences in the past and present, together with future aspirations can usefully inform the development of SRE programmes. 
Maxwell, C. (2006) 'Context and 'contextualisation' in sex and relationships education', Health Education, 106(6): 437-449.

Key words Sex education, Young people, Schools, United Kingdom

Paper type Research paper

\section{Introduction}

The importance of understanding sexual behaviour within the wider context of people's lives is increasingly being promoted in international sexual health research (Dowsett and Aggleton, 1999; Chalmers et al., 2001; Aggleton et al., 2004) as well as by those making recommendations for the development of sex and relationships education (SRE) based on close focus work with young people (Hirst, 2004). In particular, it has been suggested that SRE should be contextualised at a number of different levels - in the context of young people's actual experiences (Langille et al., 2001; Hirst, 2004), in relation to classroom and group dynamics between young people (Buston et al., 2002), and with respect to the school or organisation's commitment to SRE (Forrest, 2000; Langille et al., 2001; Wight et al., 2002). This way, not only will SRE be more meaningful but it will also facilitate stronger engagement by young people.

Recent research on young people's experiences of school-based SRE provision has identified that the teachers' confidence in the subject (Trippe, 1994; Hallfors and Godette, 2002) and their ability to manage pupil interaction (Buston et al., 2002; Hilton, 2003) are crucial for promoting student participation. Disruptive behaviour by young men (Forrest, 2000) often frustrates young people's learning from SRE provision (Langille et al., 2001). Gender-differentiated receptivity to SRE (Carter and Carter, 
Maxwell, C. (2006) 'Context and 'contextualisation' in sex and relationships education', Health Education, 106(6): 437-449.

1993; Measor et al., 1996) and the heterogeneity of experiences and diversity of attitudes possible within one group of young people (Wight and Abraham, 2000) also poses significant challenges for developing SRE. Making SRE as personally relevant to individual students as possible (Langille et al., 2001) and discussing sexual relationships with reference to the type of sexual activity and the location in which they actually occur (Hirst, 2004) is critical in promoting young people's engagement. Furthermore, the wider context that frames young people's sexual and intimate relationship attitudes and the choices they may or may not have should be taken into account when developing SRE (Warwick and Aggleton, 2002). Not only should the environments in which sex takes place be accurately portrayed, but the connection between sexual relationships and other aspects of young people's lives should be made explicit (Chalmers et al., 2001) [1].

This paper aims to illustrate how the 'context' in which young people live and their broader experiences can directly influence their sexual and intimate relationships. Drawing on interview and focus group data from 52 young people discussing past and present relationships, it aims to show how young people's past experiences, present circumstances and future aspirations play a role in explaining relationship attitudes and behaviours. Based on these findings, some recommendations for future SRE work with young people are made.

\section{Methods}


Maxwell, C. (2006) 'Context and 'contextualisation' in sex and relationships education', Health Education, 106(6): 437-449.

The findings reported on in this paper are drawn from a broader, exploratory study, conducted between 2001 and 2003, of young people's expectations and experiences of sexual and/or intimate relationships in one city in central England [2].

\section{Recruitment}

The study aimed to recruit a relatively diverse group of young people. A purposive sample of young people who might be considered especially vulnerable to sexual health problems [3] was recruited from two supported accommodation units for young people with experience of public care, homelessness, offending, or substance misuse problems; a young offenders' institution; a homeless drop-in project; and a young mothers' support group. A second sample of less vulnerable young people was recruited from two fee-paying boarding schools in which young people were studying for GCE 'A' Levels -- one of the highest qualifications available at English secondary school level.

Potential participants were informed about the research by members of staff and through the dissemination of information leaflets. All participants (except those at the young offenders' institution) were offered the opportunity to take part in a focus group, in depth interview or both. In all, fifty-two young people (30 women and 22 men) agreed to participate, ranging in age from 16 to 23 years (average 18 years). Thirty-five participants were drawn from agencies working with vulnerable young people (18 of whom were men). Of the 17 less vulnerable young people (all full-time boarders) who participated in the study, only four were men. Despite intensive efforts, including sending individualised letters about the project to all potential male participants and 
Maxwell, C. (2006) 'Context and 'contextualisation' in sex and relationships education', Health Education, 106(6): 437-449.

form teachers, promoting participation in the study, it proved difficult to elicit the involvement of young men at the fee-paying boarding schools involved in the research.

Although ethnicity makes a contribution to current frameworks of social 'vulnerability' (Aggleton et al., 2004), the exploratory nature of the broader study meant that ethnicity was not used as a key criterion for recruitment to the research. Thus, while eight of the twelve vulnerable young men and five of the thirteen less vulnerable young women were from minority ethnic communities, the range of ethnicities represented (AfricanCaribbean, African, Chinese, Pakistani, Eastern European) and the lack of comparative numbers of young vulnerable women and less vulnerable young men from specific minority ethnic communities, makes an analysis of the influence of ethnicity on sexual and intimate relationship attitudes and experiences impossible in this study.

Data collection and analysis

Five focus groups were conducted, with a total of 19 young people taking part. At the first supported accommodation unit, a series of three focus groups was advertised to residents, who were asked to 'turn up' if they wanted to take part in one or more of these groups. This resulted in two mixed-sex groups with an average of four participants per group and one young men-only group of four being run. Only two young men took part in more than one focus group discussion.

Another focus group was run with the all five members of a young mothers' support group that was held in a community setting. The fifth and final focus group take place 
Maxwell, C. (2006) 'Context and 'contextualisation' in sex and relationships education', Health Education, 106(6): 437-449.

at the first fee-paying boarding school, where four young women who identified themselves as friends, asked to take part in a group discussion. No other young people at the two boarding schools or at the second supported accommodation unit opted for a focus group discussion, indicating to the researcher a preference to be interviewed on their own. At the young offenders' institution young men were not offered the option of a focus group due to logistical difficulties.

All focus groups and interviews were undertaken by the author. Focus group discussions were aimed at exploring young people's current sexual and intimate relationship attitudes and expectations. This data was compared with, and augmented by, the narratives obtained from in-depth interviews with 38 young people ( 22 of whom were vulnerable and five of whom had already participated in a focus group).

The interview schedule was structured around a participant's account of past and present sexual or intimate relationship attitudes and experiences. Interviews lasted between 60-90 minutes. Attitudes and experiences of SRE did not form part of the focus group or interview schedule, and participants rarely introduced this topic during their discussions.

Focus groups and interviews were transcribed verbatim and participants' names were changed to ensure anonymity. For this paper, data analysis focused on young people's descriptions of their relationship attitudes, reasons identified for initially becoming involved with another person, and their assessment of the quality of specific relationships they had experienced. The focus of the content analysis of young people's 
Maxwell, C. (2006) 'Context and 'contextualisation' in sex and relationships education', Health Education, 106(6): 437-449.

narratives was on identifying whether attitudes to, and experiences of, relationships appeared to change over the course of youth, as reported by young people, and whether attitudes and experiences appeared to differ across the sample according to the gender or level of vulnerability of a participant. . During the analysis, attention was also paid to the possible impact of the researcher's age and background on the stories shared by participants.

\section{Findings}

This study found that young people's sexual and intimate relationships seemed to be strongly influenced by the wider context in which they were occurring. A young person's past experiences and behaviours, the current situation and environment in which they found themselves, and their future aspirations were shown to affect the relationship attitudes and experiences described by participants. The various factors that the majority of young people suggested had influenced the type of relationships they experienced both in the past and in the present are outlined below.

In the past-factors affecting relationship attitudes and experiences

During the research, young people often discussed relationship experiences that had occurred up to two years prior. In these accounts three factors emerged as variously influencing young people's attitudes or experiences: peer group norms, the need for protection and companionship, and previous negative relationship experiences. 
Maxwell, C. (2006) 'Context and 'contextualisation' in sex and relationships education', Health Education, 106(6): 437-449.

The influence of the peer group on a young person's relationship attitudes and behaviour could take numerous forms. Among young vulnerable men especially, peer groups often applied verbal pressure by teasing those who were not sexually active yet. Frank (aged 18, interviewed at supported accommodation unit 1) recalled that 'everyone at school used to take the piss because I hadn't lost it [his virginity]'. Young men felt under pressure not just to lose their virginity and overcome that 'milestone' (Taylor, aged 18 , interviewed at the young offenders' institution), but also to secure a high numbers of sexual conquests in order to establish their status within their peer group. Similar views were expressed by a small minority of the less vulnerable young women:

'I started sleeping with guys when I was 14 ...I felt peer pressured...because all my friends were doing it and I thought it was really cool. Because I was like one of the most popular people in the year, [although having sex early] wasn't kind of the most respected, I think it was envied...it was like a competition to see who could be the most popular in my friends and I was determined to be that girl...'

(Shelley, aged 17, interviewed at boarding school 1)

Many early patterns of sexual behaviour reported by young people seemed to have been strongly influenced by peer group norms governing sexual activity and the way groups of friends spent their free time. In response to a question about how he spent his spare time, Lester (aged 17, interviewed at the young offenders' institution) recounted that a 'normal thing to do' among his peer group was a sexual practice they called 'battery'. 'Out of boredom' a group of friends would invite a young woman over to have sex with each member of the group ('one after the other'). Lester described these experiences 
Maxwell, C. (2006) 'Context and 'contextualisation' in sex and relationships education', Health Education, 106(6): 437-449.

not as 'enjoyment' but as 'the adrenaline of [a group of friends] all having fun at the same time... and [being able to] talk about it after'. While this form of activity was not reported by any other young people in the study, anecdotal evidence released by the England Youth Justice Board has indicated that 'battery' may be common practice within some gang cultures in deprived inner-city communities (Hill and Thompson, 2004).

A young man, in a mixed-sex focus group that took place in the first supported accommodation unit, described how one night he had 'felt pressured [to have sex with someone] because I was on my own and everyone else was in couples; [so] it was either go to bed or go and get a girl...I felt stupid 'coz I was sitting there and everyone else was carrying on [kissing and petting] ...I was like oh my God, give me another bottle [of beer]'. This young man went on to describe how he ended up spending the night with a former girlfriend with whom he had previously vowed never to have sex with again.

On the whole, vulnerable young people participating in the study reported experiencing sexual relationships earlier (two to three years) and more frequently than those young people recruited from fee-paying boarding schools. Such a pattern could be explained in part by vulnerable young people's significantly different experiences during their youth. The majority had left home at an early age, had not completed their education, and felt displaced from their local community due to periods of imprisonment or being taking into the care of the local authority. In such a context, young people often described an urgent need for involvement in a romantic relationship both for the purposes of companionship, 
Maxwell, C. (2006) 'Context and 'contextualisation' in sex and relationships education', Health Education, 106(6): 437-449.

'The minute you leave school you start to mature coz you've got to coz you are starting real life... 'coz you have got to go on the streets and that...you've got to grow up... I reckon it's because you have got to start dealing with the world and you want someone else to do it with you...'

(Young man in single-sex focus group, supported accommodation unit 1)

as well as protection from abuse and destitution, especially if they were female and homeless:

'As soon as I was finished with one bloke, I would go with another one and another one...but that was because I didn't think I could look after myself. I felt I was - I am - still insecure... I was always going from one bloke to another bloke to basically support me, look after me, be there for me and that.'

(Chloe, aged 21, interviewed at supported accommodation unit 2)

Less vulnerable young people's relationships did not appear to be as strongly influenced by the need for companionship and/or protection, but arguably aligned to such factors was a narrative shared by over half of the less vulnerable young women which suggested that past relationships had been pursued as a way bolstering their 'selfesteem' (Lea, aged 19, interviewed at boarding school 1).

Among the majority of young women in both the vulnerable and less vulnerable groups sampled, a third factor seemed to have influenced relationship attitudes and experiences 
Maxwell, C. (2006) 'Context and 'contextualisation' in sex and relationships education', Health Education, 106(6): 437-449.

in the past - namely, earlier negative sexual and/or intimate relationships experiences.

Often these experiences continued to have some bearing on attitudes held and experiences described in the present too.

Young women in the study, especially those from the vulnerable sample, also described past experiences of childhood sexual abuse (disclosed by five of the 22 young women sampled), experiences of sexual assault during their youth (five of the ten vulnerable young women) and experiences of domestic violence in their intimate relationships (all vulnerable young women sampled). This level of violence reported by young women was not mirrored in young men's narratives of their relationships, although a minority did describe events in which they had been violent towards a partner or had pressured a young woman into having sex.

Experiences of violence appeared to influenced young women's later attitudes to men ('I just started to realise that men were using $m e$ ' - Chloe, aged 21, interviewed at supported accommodation unit 2; 'I was generally very cynical about guys ...I didn't trust them' - Lindsey, aged 19, interviewed at boarding school 1) as well as their expectations for future relationships ('I wasn't gonna go out with anyone for ages, mainly [because of] the violence...I now want a talking relationship [where we communicate]' - Zoe, aged 21, interviewed at supported accommodation unit 2).

Among the less vulnerable sample of young women, although their negative experiences with men were less extreme, half (six out of 12) had experienced sexual pressure from partners and the majority had felt betrayed by a previous boyfriend as a 
Maxwell, C. (2006) 'Context and 'contextualisation' in sex and relationships education', Health Education, 106(6): 437-449.

result of his infidelity. Such experiences seemed to confirm their wary and stereotypical attitudes towards men ('I was anxious about the fact that it is so easy for men [to be unfaithful], they can [have sex] and not be emotionally involved' - Rachel, aged 18, interviewed at boarding school 1) and for almost half of the less vulnerable young women influenced the speed at which they searched out or agreed to embark on a new relationship, often opting to remain single for a period of time following a negative experience. Two of these young women specifically recounted that they had consciously withdrawn from being involved in relationships for a period of time in order to challenge the reputations they had gained as a 'slapper'. Shelley (aged 17, interviewed at boarding school 1) explained, 'basically I got a really bad reputation, two or three years ago, coz I was going out with people, pulling them [kissing and/or having sex], I got a really bad name, so I got out town for like 8 months [did not go out in the evenings]'.

The present - factors affecting relationship attitudes and experiences

All young people in the study spent time describing and reflecting on their current situations and any relationships they were involved in. During these narratives, three main factors seemed to influence their attitudes and experiences: access to potential partners, other priorities in their lives and uncritical assessments of current relationships. 
Maxwell, C. (2006) 'Context and 'contextualisation' in sex and relationships education', Health Education, 106(6): 437-449.

The majority of young women in the first fee-paying boarding school, which was a single-sex school, said that finding a potential partner and having the time to get to know them on neutral ground was a particular challenge.

'I am hopeful with the whole university thing, because we [male and female students] will all be in one place, and you can be friends with people, and then you can choose [a romantic partner] from a friend - I think that is what I lack really in an all girl's school...'

(Chrissie, aged 17, interviewed at boarding school 1)

The rules by which young people at both boarding schools had to abide restricted their ability to pursue current relationships they were involved in. Time to go off the school site was limited and while at school young people were closely monitored. Steven (aged 18) interviewed at the mixed-sex boarding school complained at the lack of privacy ('the problem for me is that there is nowhere really to meet...there's nowhere to sit down and just have a talk with someone') and the rules that governed male-female interaction ('they [the boarding school] have all these rules...the six inch rule where you are not allowed to be touching'). Steven was once caught with his girlfriend in his bedroom, and although 'we weren't doing much...I only had my top off', they had been suspended for three weeks.

For the young men in the young offenders' institution, access to potential female partners was also limited. Most of the young men had decided to end their then ongoing relationships before their prison sentence had begun: 
Maxwell, C. (2006) 'Context and 'contextualisation' in sex and relationships education', Health Education, 106(6): 437-449.

'As soon as I come to prison I just said there is no point having a girlfriend there - no girl is going to wait for me...so I just let them go.'

(Len, aged 17, interviewed at the young offenders' institution)

Young men appeared to prefer to be unattached than feel powerless to prevent what they saw as an unavoidable infidelity on the part of a girlfriend. Although only two young men said they had a long-term girlfriend 'waiting for you to get out' (Jessie, aged 18, interviewed at the young offenders' institution), many described keeping in contact via letters or telephone with female acquaintances and potential girlfriends. Despite the lack of physical contact with women at the time of the study, all the young men appeared to spend a considerable proportion of their time reflecting on past relationship experiences, as well as planning and fantasising about 'when I get back outside' (Darrell, aged 17, interviewed at the young offenders' institution). The time to reflect led almost half of the young men to decide that in the future, once they had left prison, they would pursue relationships for different reasons than those that had motivated their experiences in the past:

'I think that now I would rather be in a relationship than just have casual partners'

(Taylor, aged 18, interviewed at the young offenders' institution).

A third of the young people (the majority of whom were from the less vulnerable sample) discussed having other goals at the time of the study that they were currently 
Maxwell, C. (2006) 'Context and 'contextualisation' in sex and relationships education', Health Education, 106(6): 437-449.

prioritising over embarking on an intimate relationship. Those young people in their final year of GCE 'A' Levels at the two boarding schools especially, often expressed anxiety about being 'distracted' (Angela, aged 18, interviewed at boarding school 1) from their studies, fearing a relationship during such a crucial time of their education would use up precious time and emotional energy:

'I can't cope with co-dependence in final year of 'A' Levels and...I am really ambitious with my Art, I really want to go somewhere with it, so I am fairly focused on university...so I don't really have time for anything that will leave me upset or ... you know...scarred...'

(Chrissie, aged 17, interviewed at boarding school 1)

Although the majority of young people recruited through the two supported accommodation units were currently involved in an intimate relationship, Chloe (aged 21) had made a conscious decision to be 'independent' until she had successfully overcome her heroin addition. 'With me like having a [heroin] habit...I've got my own problems and I don't want to take nobody else's on board 'cause it hard enough dealing with my own'.

For the less vulnerable young people and the vulnerable young men, access to potential partners and a current focus on other priorities appeared to most strongly influence current relationship attitudes. For the vulnerable young women, however, another factor emerged as dominating narratives of current experiences. All the vulnerable young women, except for Chloe, reported being in a relatively serious and committed 
Maxwell, C. (2006) 'Context and 'contextualisation' in sex and relationships education', Health Education, 106(6): 437-449.

intimate relationship at the time of the study. Compared to their reflective and critical narratives about past experiences and boyfriends, their current partnerships seemed to escape such an assessment and were often viewed through more 'rose-tinted glasses'.

Caro (aged 21, interviewed at supported accommodation unit 1) asserted several times during her interview that her boyfriend was 'the most perfect person in the world'. Such a sentiment was also echoed in Sarah's interviews ('I can't really say that there is anything that doesn't work well for us, really' - Sarah, aged 23, interviewed at supported accommodation unit 1). Despite such positive evaluations of their current partners, both young women described experiences that suggested incidents of sexual pressure (Sarah), times when their feelings had been neglected (Caro and Sarah) and conflicting future priorities between them and their boyfriends (both young women). Interestingly, during the process of the interview, as these two young women spent more time discussing and reflecting on their current relationships, the positive and negative traits of their partners and the way in which they interacted with them, a more critical and balanced assessment of their relationship sometimes seemed to filter through.

In the future -factors affecting relationship attitudes and experiences

Young people's aspirations for the immediate and the long-term future seemed to affect both their current and prospective attitudes to sexual and intimate relationships. All the young people recruited at the two boarding schools assumed they would be going to university and afterwards embarking on a career. This had three main consequences for 
Maxwell, C. (2006) 'Context and 'contextualisation' in sex and relationships education', Health Education, 106(6): 437-449.

their attitudes to relationships. Many young people described delaying emotional investment in a relationship in order to be better able to focus on securing their GCE 'A' Levels (as discussed earlier). A few of the study participants also suggested that the pool of potential partners would be greater and more interesting at university, providing them with yet a further reason to wait.

'[Going to university] I think I'll probably change my mind about relationships and become a little bit more open-minded about them'.

(Joe, aged 17, interviewed at boarding school 2)

Finally, the impending change in circumstances meant at least three of the less vulnerable study participants were planning the dissolution of their current relationship. For Steven (aged 18, interviewed at boarding school 2), the fact that his girlfriend was two years younger than him, meant that his transition to university would have to involve ending their two-year long relationship. Despite being upset at the prospect of ending his current relationship, he was also excited about the future and was already forming expectations of what type of relationship he might engage in next: 'you know a new environment, so many new people, lots of drinking and you know partying...I think it will probably be quite a big step; I will be single again...I don't think I will be able to commit myself straight away into a huge relationship'. Rachel (aged 18, interviewed at boarding school 1) was also deeply committed to her current boyfriend, but speculated that their futures lay in separate directions and that their different social and cultural backgrounds would prove too great to overcome in the future. 
Maxwell, C. (2006) 'Context and 'contextualisation' in sex and relationships education', Health Education, 106(6): 437-449.

The young men recruited from the supported accommodation units and the young offenders' institution offered a less clearly developed vision of their futures. Some of the young men spoke about undertaking further education or finding employment, while others did not feel able to plan beyond what might happen tomorrow or following their initial release from prison. Uncertainty about the future, or a lack of interest in, or ability to, plan for the future, meant that some young men felt unable to fully commit to a current relationship:

'Circumstances always change; doesn't necessarily mean we [him and his girlfriend] are going to be together tomorrow, or even in a year's time.' (Warren, aged 18, interviewed at supported accommodation unit 1)

Vulnerable young women's descriptions of their futures tended to centre around marriage and children.

'It's all I have ever wanted: to have my own babies and not to live in a hostel and stuff like that...I know I will do it.'

(Chloe, aged 21, interviewed at supported accommodation unit 2)

Four of the vulnerable young women were engaged at the time of interview. Vulnerable young women's expressed need for companionship and protection, as well as future aspirations that focused almost solely on marriage and children (as detailed above), may explain why many of these young women reflected relatively uncritically on their current relationships. 
Maxwell, C. (2006) 'Context and 'contextualisation' in sex and relationships education', Health Education, 106(6): 437-449.

\section{Discussion}

Young people in the study discussed a range of factors that seemed to influence their sexual and intimate relationship attitudes and experiences. However, these factors did not affect all study participants equally and were not consistency influential across the whole period of youth. For instance, peer groups seemed to play a particularly large role in influencing the experiences reported by the vulnerable young men in their early youth. This finding is supported by Wight's (1996) research on Glaswegian workingclass young men's relationship experiences, Corlyon and McGuire's (1999) study of young people in local authority care, and Walker and Kushner's (1999) analysis of the peer group's waning influence on young men's identity development over time.

A second illustration of a factor differentially affecting young people in this study, was the impact of early experiences of relationships on later attitudes and the choices made. This appeared particularly influential for some of the less vulnerable young women who often made a conscious decision to abstain from further involvement with young men for a considerable period of time, following a previous negative experience. Similarly, access to potential partners appeared important only in the current relationship experiences described by both the young men recruited through the young offenders' institution and the young men and women at the two boarding schools. It may be that in the future, when these young men left prison, or the less vulnerable young men and women went off to university, that this factor would lose its relevance. 
Maxwell, C. (2006) 'Context and 'contextualisation' in sex and relationships education', Health Education, 106(6): 437-449.

While some factors seemed more prominent for certain groups of young people, and at different points in time, other influences continued to affect young people's attitudes and choices consistently over time. Yet the manner in which they did so differed.

For example, the majority of vulnerable young people reported experiences that previous research has suggested may be linked to an earlier transition into adulthood (leaving education, living independently, early sexual activity) (Jones, 2002). Such a transition seemed to push young women especially, during their early youth into relationships with men in order to secure protection from abuse and loneliness. When these same young women discussed their future relationship plans, the influence of an accelerated transition to adulthood continued to manifest itself in their attitudes, as almost half of the young women were engaged to be married.

Less vulnerable young women, on the other hand, were on the whole still financially supported by their parents, were fully engaged in their education, focused on going to university, and described a commitment to developing their career before considering marriage (c.f. Hillier et al., 1999). The hesitancy to invest emotionally in a relationship because of other current priorities (particularly in relation to educational attainment) has been noted in other studies and been linked to youth transitions (Nielsen and Rudberg, 2000; Thomson and Holland, 2002; Thomson et al., 2003).

Some limitations 
Maxwell, C. (2006) 'Context and 'contextualisation' in sex and relationships education', Health Education, 106(6): 437-449.

This small scale, in-depth qualitative study has been able to identify a range of factors that influenced the sexual and intimate relationship attitudes and experiences of the young people concerned. These exploratory findings, while providing a useful basis for developing future work with young people, would need to be further investigated with a larger and more representative sample to determine their typicality and how far they may be generalised. In particular, less vulnerable young men, whom it proved especially challenging to engage in the study, would need to provide the focus of future research.

\section{SRE recommendations}

Findings from this study therefore reinforce the importance of ensuring that variations in young people's sexual and intimate relationship experiences and aspirations are properly taken into account in developing and implementing SRE in school and out-ofschool settings (Carter and Carter, 1993; Wight and Abraham, 2000; Hirst, 2004). Based on the findings reported here, it is evident that often quite different factors can influence young people's attitudes and experiences over the course of their youth. If SRE is to do more than simply impart information on pregnancy and the prevention of sexually transmitted infections, and hopes to enable young people to make 'informed choices' - a term frequently used in the broader sex and relationships education literature - e.g. Wight and Abraham, 2000 - then supporting young people in reflecting on their sexual relationships and in identifying possible factors that have influenced their experiences, will require the use of what might be described as a more contextual approach (Chalmers et al., 2001; Warwick and Aggleton, 2002; Hirst, 2004). 
Maxwell, C. (2006) 'Context and 'contextualisation' in sex and relationships education', Health Education, 106(6): 437-449.

Historical, situational and contextual factors influence young people's sexual and intimate relationships differently, and at different points in their youth. This should directly inform the issues SRE addresses at a particular point in time, in ways sensitive to the needs of different groups of young people (Langille et al., 2001). For instance, in early youth the influence of the peer group should be a crucial focus for SRE aimed at young men. Similarly, for less vulnerable young women, many of whom displayed particularly wary and somewhat untrusting attitudes towards young men following previous negative experiences, mixed-sex small group work may be beneficial in enabling the development of less stereotypical attitudes.

For young people who are homeless or living in public care, SRE should focus on how their circumstances and experiences influence their current and future expectations of the purpose of intimate relationships. Young vulnerable women in particular, should explore how the environment in which they are living may arguably curb their ability to make 'choices', because of their need for protection and companionship, as well as their often restricted aspirations for the future because of the lack of educational opportunities that are available to them.

The context in which an SRE programme is offered should also influence its content. In young offenders' institutions, for instance, as suggested by a few of the young men in this study, young people may be feel more able to reflect on their past experiences and consider their future aspirations because they are temporarily removed from their environment. Thus, working with young men while they are incarcerated may provide 
Maxwell, C. (2006) 'Context and 'contextualisation' in sex and relationships education', Health Education, 106(6): 437-449.

an ideal opportunity for in depth group- and one-to-one discussions and education around issues related to sexual and intimate relationships.

Based on the findings reported here, SRE work with young people should be contextualised by focusing on age-appropriate and personally relevant attitudes and experiences. By supporting young people to reflect on the factors that have influenced their past sexual and intimate relationship experiences, by facilitating a more critical evaluation of current attitudes and experiences (as participation in this study appeared to do for Caro and Sarah), and by working together with young people to proactively develop aspirations and practice the relevant skills needed, SRE should be able to make a valuable contribution to promoting young people's sexual health and well-being in the future.

\section{Notes}

[1] Some of the UK policy and guidance documents related to SRE do suggest that programmes of work should place sex and relationships in a wider context, see for instance advice given to schools by the Department for Education and Employment (2000) to 'link sex and relationships education with issues of peer pressure and other risk-taking behaviour' (p. 10), that SRE should be made 'relevant' to boys as well (p. 11), and that SRE policies ought to be 'culturally appropriate' (p. 12). However, the range of ways, and the various levels at which SRE could be contextualised is not teased out in current guidance around SRE. 
Maxwell, C. (2006) 'Context and 'contextualisation' in sex and relationships education', Health Education, 106(6): 437-449.

[2] The broader study aimed to operationalise the concept of social 'vulnerability' developed in the sexual health literature (Delor and Hubert, 2000; Aggleton et al., 2004) in order to explore the degree to which such a framework can help to accurately differentiate between sexual and intimate relationships reported by young people who might be considered 'vulnerable' and those who might be consider 'less vulnerable'.

[3] Young people $n$ England are frequently defined as 'vulnerable' if they have been in contact with local authority social services departments (Pawlby et al., 1997) and/or have had experience of homelessness, youth offending and/or teenage parenthood (Hughes, 1999). Middle class young people, and those attaining educational qualifications, on the other hand, are generally viewed as less vulnerable to sexual health problems (Hughes, 1999), as they are likely to delay the onset of sexual intercourse and are less likely to become teenage parents (Wellings et al., 2001).

\section{References}

Aggleton, P., Chase, E. and Rivers, K. (2004) HIV/AIDS Prevention and Care among Especially Vulnerable Young People, Safe Passages to Adulthood programme, University of Southampton, Southampton. Available at http://www.socstats.soton.ac.uk/cshr/guidesToProgramme.html

Buston, K., Wight, D. and Hart, G. (2002), "Inside the sex education classroom: the importance of context in engaging pupils", Culture, Health and Sexuality, Vol. 4 No. 3, pp. 317-35.

Carter, S. M. and Carter, D. S. G. (1993), "Gender differentiated receptivity to sexuality education curricula by adolescents", Health Education Research: Theory and Practice, Vol. 8 No. 2, pp. 233-43. 
Maxwell, C. (2006) 'Context and 'contextualisation' in sex and relationships education', Health Education, 106(6): 437-449.

Chalmers, H., Stone, N., and Ingham, R., with Aggleton, P., Cleland, J., Partridge, R. and Castle, S. (2001), Dynamic Contextual Analysis of Young People's Sexual Health, Safe Passages to Adulthood programme, University of Southampton, Southampton. Available at http://www.socstats.soton.ac.uk/cshr/SafePassagesDCA1.html

Corlyon, J. and McGuire, C. (1999), Pregnancy and Parenthood - the views and experiences of young people in public care, National Children's Bureau, London.

Delor, F. and Hubert, M. (2000), "Revisiting the concept of "vulnerability", Social Science and Medicine, Vol. 50, pp. 1557-1570.

Department for Education and Employment (2000), Sex and Relationship Education Guidance, Department for Education and Employment, Nottingham.

Dowsett, G. and Aggleton, P. (1999) "Young people and risk-taking in sexual relations", in Aggleton, P., Dowsett, G., Rivers, K. and Warwick, I. Sex and Youth: contextual factors affecting risk for HIV/AIDS, UNAIDS, Geneva. Available at http://www.unaids.org/html/pub/publications/irc-pub01/jc096-sex_youth_en_pdf.pdf Forrest, S. (2000), “'Big and tough': boys learning about sexuality and manhood”, Sexual and Relationship Therapy, Vol. 15 No. 3, pp. 247-61.

Hallfors, D. and Godette, D. (2002), "Will the 'principles of effectiveness' improve prevention practice? Early findings from a diffusion study", Health Education Research: Theory and Practice, Vol. 17 No. 4, pp. 461-70.

Hill, A. and Thompson, T. "Police reopen two thousand gang rape cases", The Observer, Sunday April 4, 2004.

http://observer.guardian.co.uk/uk news/story/0,6903,1185394,00.html (accessed on 10/10/05).

Hillier, L., Harrison, L. and Bowditch, K. (1999), “'Neverending love' and 'blowing your load': the meanings of sex to rural youth", Sexualities, Vol. 2 No. 1, pp. 69-88. Hilton, G. L. S. (2003), “Listening to the boys: English boys' views on the desirable characteristics of teachers or sex education", Sex Education, Vol. 3 No. 1, pp. 33-45. 
Maxwell, C. (2006) 'Context and 'contextualisation' in sex and relationships education', Health Education, 106(6): 437-449.

Hirst, J. (2004), “Researching young people's sexuality and learning about sex: experience, need, and sex and relationships education", Culture, Health and Sexuality, Vol. 6 No. 2, pp. 115-29.

Hughes, K. (1999), Reducing the Rate of Teenage Conceptions - Young People's Experiences of Relationships, Sex and Early Parenthood: Qualitative Research, Health Education Authority, London.

Jones, G. (2002), The Youth Divide: Diverging Paths to Adulthood, York Publishing Service for the Joseph Rowntree Foundation, York.

Langille, D., MacKinnon, D., Marshall, E. and Graham, J. (2001), "So many bricks in the wall: young women in Nova Scotia speak about barriers to school-based sexual health education", Sex Education, Vol. 1 No. 3, pp. 245-57.

Measor, L., Tiffin, C. and Fry, K. (1996), "Gender and sex education: a study of adolescent responses", Gender and Education, Vol. 8 No. 3, pp. 275-88.

Nielsen, H. B. and Rudberg, M. (2000), “Gender, love and education in three generations", The European Journal of Women's Studies, Vol. 7, pp. 423-453.

Pawlby, S. J., Mills, A. and Quinton, D. (1997), "Vulnerable adolescent girls: oppositesex relationships", Journal of Child Psychology and Psychiatry, Vol. 38 No. 8, pp. 90920.

Thomson, R. and Holland, J. (2002), "Imagined adulthood: resources, plans and contradictions", Gender and Education, Vol. 14 No. 4, pp. 337-50.

Thomson, R., Henderson, S. and Holland, J. (2003), "Making the most of what you've got? Resources, values and inequalities in young women's transitions to adulthood", Educational Review, Vol. 55 No. 1, pp. 33-46.

Trippe, H. (1994), "School sex education: can DHAs help to bridge the divide between theory and practice?", Health Education Journal, Vol. 53, pp. 140-6.

Walker, B. M. and Kushner, S. (1999), “The building site: an educational approach to masculine identity", Journal of Youth Studies, Vol. 2 No. 1, pp. 45-58.

Wellings, K., Nanchahal, K., Macdowall, W., McManus, S., Erens, B., Mercer, C. H., Johnson, A. M., Copas, A. J., Korovessis, C., Fenton, K. A. and Field, J. (2001), 
Maxwell, C. (2006) 'Context and 'contextualisation' in sex and relationships education', Health Education, 106(6): 437-449.

"Sexual behaviour in Britain: early heterosexual experience", Lancet, Vol. 358, pp. 1843-50.

Warwick, I. and Aggleton, P. (2002) The Role of Education in Promoting Sexual and Reproductive Health, Safe Passages to Adulthood programme, University of Southampton, Southampton. Available at http://www.socstats.soton.ac.uk/cshr/guidesToGood.html

Wight, D. (1996), "Beyond the predatory male: the diversity of young Glaswegian men's discourses to describe heterosexual relationships", in Adkins, L. and Merchant, V. (Eds), Sexualizing the Social: Power and the Organisation of Sexuality, MacMillian, London.

Wight, D. and Abraham, C. (2000), "From psycho-social theory to sustainable classroom practice: developing a research-based teacher-delivered sex education programme", Health Education Research: Theory and Practice, Vol. 15 No. 1, pp. $25-$ 38.

Wight, D., Raab, G. M., Henderson, M., Abraham, C., Buston, K., Hart, G., and Scott, S. (2002), "Limits of teacher delivered sex education: interim behavioural outcomes from a randomised trial”, British Medical Journal, Vol. 324 No. 7351, pp. 1430-33. 
Maxwell, C. (2006) 'Context and 'contextualisation' in sex and relationships education', Health Education, 106(6): 437-449.

\section{Acknowledgements}

I would like to thank Ian Warwick, Janet Boddy and Peter Aggleton for their helpful comments on earlier drafts of this paper. 